\title{
Pathways from built environment to health: Connecting behavior and exposure-based impacts
}

\author{
Lawrence D. Frank, Ph.D ${ }^{\text {a }}$ \\ Nicole Iroz-Elardo, Ph.D ${ }^{b}$ \\ Kara E. MacLeod, DrPH ${ }^{\mathrm{c}}$ \\ Andy Hong, Ph.D ${ }^{\mathrm{d}^{*}}$ \\ ${ }^{a}$ University of British Columbia \\ School of Population and Public Health \\ School of Community and Regional Planning \\ Room 360B - 2206 East Mall \\ Vancouver BC Canada V6T 1 Z3 \\ ${ }^{\mathrm{b}}$ University of Arizona \\ School of Landscape Architecture and Planning \\ 1040 N. Olive Road \\ Tucson, Arizona 85719 \\ ${ }^{\mathrm{c}}$ University of California, Los Angeles \\ Fielding School of Public Health \\ Department of Community Health Sciences \\ Department of Health Policy and Management \\ 650 Charles E. Young Dr. S., 26-051 CHS Box 951772 \\ Los Angeles, CA, 90095-1772 \\ ${ }^{d}$ University of Oxford \\ The George Institute for Global Health, \\ Nuffield Department of Women's \& Reproductive Health \\ Hayes House, 75 George Street \\ Oxford, OX1 2BQ, United Kingdom
}

*Corresponding Author

andyhong@gmail.com

andy.hong@georgeinstitute.ox.ac.uk 


\title{
Pathways from built environment to health: Connecting behavior and exposure-based impacts
}

\begin{abstract}
Background and Purpose: A growing body of evidence documents multiple ways in which land use and transportation investments influence health. To date, most evidence linking the built environment to health either focuses on behavioral change or environmental exposures. Few studies simultaneously assess how behavior and exposure-based impacts of the built environment interact. This is concerning as increased walkability and transit access can possibly lead to increased exposure to air pollution and injury risk.
\end{abstract}

Method: This paper synthesizes recent research on behavior and exposure-based mechanisms that connect land use and transportation investments with various health outcomes. Exploring the nexus between these pathways provides a framework to identify priority areas for research to inform policies and investments.

Results: The most studied pathway articulates how land use and transportation can support healthy behaviors, such as increased physical activity, healthy diet, and social interactions. The second pathway articulates exposure to harmful substances and stressors and potential differential impacts by travel modes. Increased rates of active travel lead to lower generation of vehicle emissions and kilometers traveled; but may actually result in increased exposure which may have adverse effects on sensitive populations such as elderly and youth. Unhealthy exposures have historically concentrated in areas where the most disadvantaged reside - along major transportation corridors where land is cheapest and more affordable housing is located.

Implications: A high priority for future research is to examine mechanisms that spatially link built environment and chronic disease. More longitudinal evidence is required inclusive of biomarker data within clinical trials to isolate independent and interactive effects of biological and neurological mechanisms from behavioral and exposure related impacts of the environment. Downstream impacts of the built environment on healthcare utilization and costs and workforce productivity is required for policy makers to justify the major investments required to plan or retrofit communities.

\section{Highlights}

- Synthesizes recent evidence on the link between built environment and health

- Highlights the need to capture both behavior and exposure-based impacts

- Few studies explicitly link built environment factors with clinical end points

- Need longitudinal evidence that assesses unique and collective impacts of environmental and biological effects on disease and cost.

\section{Keywords}

Built environment; physical activity; air pollution; safety; behavior; exposure 


\section{INTRODUCTION}

Characteristics of the built and natural environment shape our travel options and activity patterns. Investments designed to support vehicular traffic typically create unhealthy and unsustainable conditions (Frumkin et al 2004; Frank et al 2003; Dannenberg et al., 2003). Suburban development characterized by low-density, single family dwelling coupled with larger than human scale urban design negate walking and bicycling (Frank, 2000; Saelens, Sallis, \& Frank, 2003). This form of development requires motorized carbon based travel while reducing physical activity and increasing obesity rates (Frank, Greenwald, Winkelman, Chapman, \& Kavage, 2010; Ladabaum, Mannalithara, Myer, \& Singh, 2014; Ngo, Frank, \& Bigazzi, 2018).

"Automobility" requires heavy investments in regionally focused road infrastructure. These investments could have lasting impacts on health by increasing levels of air pollution and injury risks. A growing body of research suggests that lower income minority populations are disproportionately affected by traffic-related pollutants (Gunier, Hertz, Von Behren, \& Reynolds, 2003; Houston, Li, \& Wu, 2014; O’Neill et al., 2003; Rowangould, 2013). Industrial toxic pollutants are often spatially concentrated and deposited where poorer minority people reside (Morello-Frosch, Pastor, \& Sadd, 2001; Pastor, Sadd, \& Hipp, 2001). "Dumping in Dixie" documented landfill proximity to poverty and popularized the concept of an unjust spatial disparity triggering the environmental justice movement (Bullard, 1997). Concentration and accumulation of environmental pollution in poor neighborhoods further aggravates the health burdens such neighborhoods already experiencing (Morello-Frosch et al 2011).

The relationship between the built environment and health is complex in nature and operates through multiple mediators and moderators (Frank et al., 2006). Identifying the causal mechanism that links built environment to health, therefore, should be tackled with a comprehensive and multidisciplinary approach. This paper speaks to this challenge of many overlapping pathways with a special emphasis on the tradeoffs that can occur in a system that is continuously changing and adapting. It begins with a brief history of previous research and updates earlier efforts to conceptualize the influence of the built environment on public health (Dannenberg et al., 2011; Dannenberg et al., 2003; Frank and Engelke, 2001; Frank et al., 2003). The paper also includes early efforts to grapple with behavior and exposure tradeoffs (Frank et al., 2006; Marshall et al., 2009), extending to monetizing health outcomes of chronic disease (American Public Health Association, 2010). An integrated framework combining behavioral and exposure-based impacts is presented to help inform a research agenda for advancing the emerging field at the nexus of urban planning, transportation, and public health. 


\section{A BRIEF HISTORY OF THE BUILT ENVIRONMENT AND HEALTH RESEARCH}

For over a century, public health and planning have worked primarily in silos to increase quality of life for individuals and communities (Corburn, 2007; Frank and Kavage, 2008). In public health, attention has turned from treating epidemics and the spread of contagion to addressing chronic disease through health promotion (Awofeso, 2004; Glanz et al 2008). In the early to mid- twentieth century, flight to the suburbs from densely population urban centers was in part a health response and the antidote to exposure to disease and pollution in Cities (Frumkin, Frank, \& Jackson, 2004). However, car dependent suburbs that provided respite from the urban ills of the early $20^{\text {th }}$ century contributed to sedentary lifestyles and a chronic disease epidemic (Ewing, Schmid, Killingsworth, Zlot, \& Raudenbush, 2003; Lopez \& Hynes, 2006).

The urban health literature suggests a nuanced picture of the built environment where cities are a 'mosaic' of health benefits and risks (Fitzpatrick and LaGory, 2003). Populations and conditions vary spatially along multiple features including transportation infrastructure, land use, access to green space, urban climate, access to healthy resources, residential segregation, and exposure to pollutants common in conditions of concentrated density (Galea and Vlahov, 2005). Each of these can impact physical and mental health. Medical science continues to document the biological and cellular effects of environmental stressors, such as air and noise pollution (Munzel et al., 2017; Wei et al., 2016) even as the variation in conditions continue at multiple spatial scales in the context of larger institutional and global structure (Northridge et al., 2003).

By 1963, the Healthy Cities movement acknowledged the social, economic, built, and natural aspects of the environment and their important influence on health and well-being (Leeuw, Duhl, \& O'Neill, 2010). Planning and health responded by joining forces at the turn of the $21^{\text {st }}$ century to articulate the built environment's influence on health behaviors and community health (Boarnet, 2006; Dannenberg et al., 2003; Frank et al., 2003; Frumkin et al., 2004). Models of collaboration uniting the professions include health in all policies, health impact assessment, social equity analysis, or the sociology of urban health. Practitioners and researchers are exploring ways in which the two disciplines can work directly together to stem the mounting chronic disease burden and build a healthier future (Fitzpatrick and LaGory, 2011; Manaugh et al., 2015; National Research Council, 2011; Rao et al., 2011; Rudolph et al., 2013; Wernham and Teutsch, 2015).

A primary focus in this growing interdisciplinary field of planning and health has been the link between the built environment, physical activity, and chronic disease with a heavy emphasis on obesity. Studies confirm physical activity's role in protecting and prescriptively 
reducing morbidity and mortality from chronic disease (Aune et al., 2016; Aune et al., 2015; Cloostermans et al., 2015; Huai et al., 2013; Kyu et al., 2016; Li and Siegrist, 2012; Rosenbaum et al., 2014; Schmid et al., 2015; Schmid and Leitzmann, 2014). Active transportation is increasingly considered as an important ingredient of healthy community planning because it offers the potential for meeting daily physical activity guidelines and mitigating climate change. Another area of focus includes air quality impacts of transportation and land use decisions. Air pollution has long been understood as a primary organizing principle in U.S. long-range transportation planning and funding. The Clean Air Act Amendments of 1991 established a regulatory framework for transportation funding based on measurable "conformity" with the health based National Ambient Air Quality Standards (Frank et al., 2003). Traffic safety has also been incorporated into transportation design. To promote walking and biking in communities and to safely accommodate vulnerable road users, Safe Routes to School, Complete Streets, and Vision Zero efforts have prompted increased attention on bicycles and pedestrians and funding for active transportation infrastructure (Cooper \& Mcmillan, 2010; Geraghty et al., 2009; Johansson, 2009).

The field of planning and health has grown rapidly over the past decades with renewed interests in the spatial aspects of health. Although 'place' has long been understood as an important determinant of health; much of the early research has focused on the compositional aspect of place, such as socioeconomic stratification and social networks (Berkman \& Kawachi, 2000). Now, the contextual aspect of place (i.e. physical built environment) has drawn much interest in both planning and public health domains (Diez Roux, 2001; Pastor \& Morello-Frosch, 2014; Rydin et al., 2012). Combined with the traditional focus on social determinants of health, the field has advanced to include spatial (Frohlich, Corin, \& Potvin, 2001) and temporal dimensions (Rainham, McDowell, Krewski, \& Sawada, 2010) as well as psychosocial and interpersonal factors theorized as the social ecological model (Sallis et al., 2006). Furthermore, recent developments in geospatial and computational technologies, such as geographic information system (GIS), global positioning system (GPS), and satellite remote sensing, have enabled collection and processing of large scale 'big data' with high spatial and temporal resolution. The amount and level of detail of emerging information has the potential to enhance our understanding of how the built environment can affect health (Chaix et al., 2013; Richardson et al., 2013). This paper contributes to this growing body of research by drawing on recent evidence and theoretical developments from a broad range of fields. 


\section{BUILT ENVIRONMENT AND HEALTH - A CONCEPTUAL FRAMEWORK}

Built environment and transportation decisions influence health outcomes through two primary paths: one is through behavior - encouraging or discouraging us to behave in ways that affect health - and the other is through exposure to harmful substances and stressors. These two pathways are depicted in Figure 1. The linkages identified in Figure 1 are not exhaustive and have varying degrees of influence. In addition, there are feedback loops that are not depicted. The healthy behavior pathway is grounded in physiology of metabolic expenditure. A metabolically healthy individual maintains "energy balance" where daily intake and expenditure of energy is matched. The other pathway is exposure - of which transportation systems are a major contributor - and stressors such as traffic, noise, and social disorder.

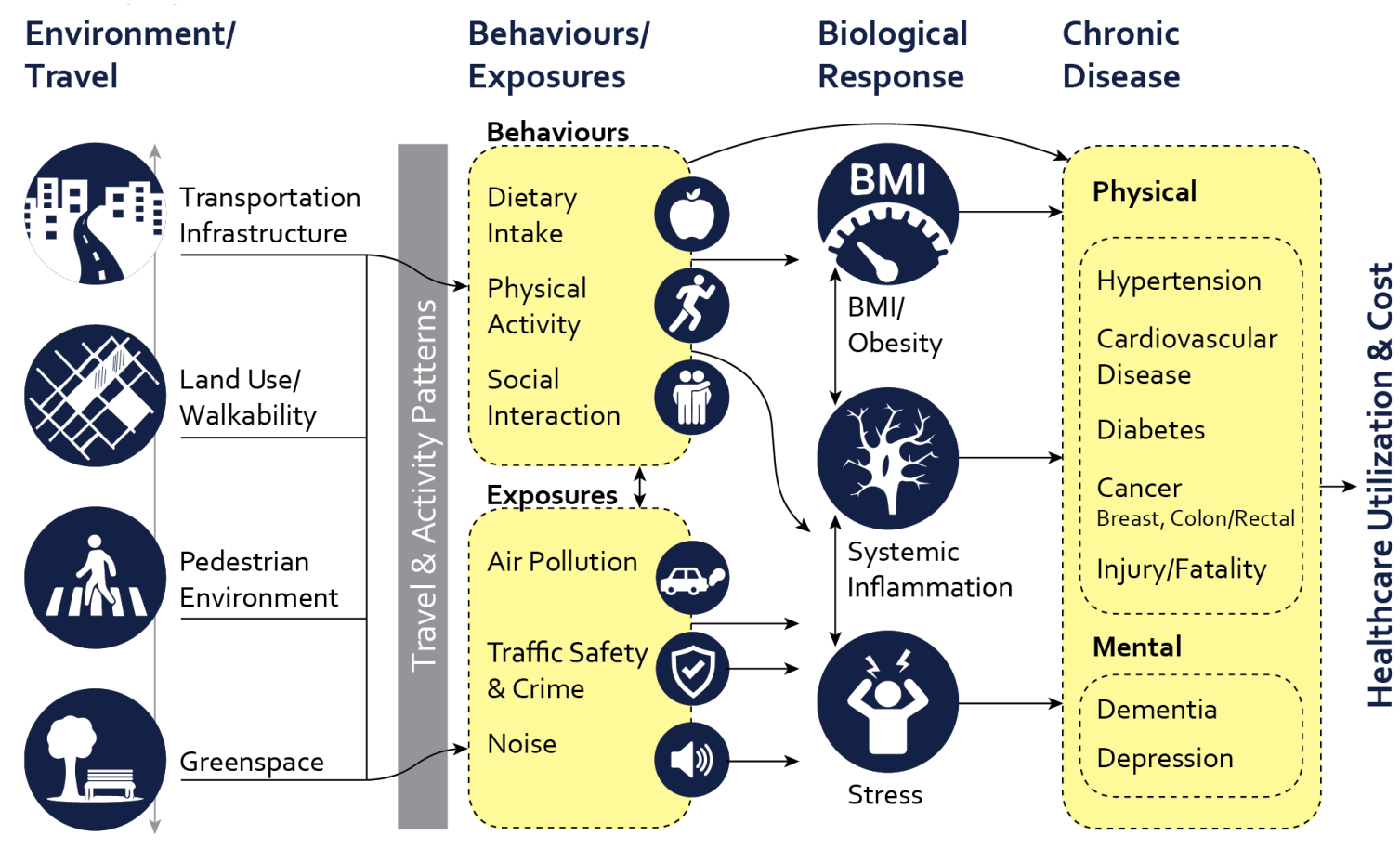

Figure 1. Causal Diagram Linking the Pathways from the Built Environment to Chronic Disease and Healthcare Costs

The health benefits of physical activity typically occur at low levels and increase with more activity. Even small changes to lifestyle and behavior can have a significant impact on health (Jakicic et al., 2018; Zheng et al., 2009). Walking is an activity that individuals, across the life-span, can participate to reduce the risk of all-cause mortality (Kelly et al., 2014). Low levels of physical activity and a sedentary lifestyle - one that rarely increases energy expenditures significantly above a resting rate - increase chronic disease risks, including coronary heart 
This paper was accepted by Journal of Transport and Health. This is an author accepted version.

disease, hypertension, diabetes, osteoporosis, breast cancer, colon cancer, anxiety, depression and dementia (de Rezende et al., 2014; Kim et al., 2013; Powell et al., 2011; Teychenne et al., 2014; Wilmot et al., 2012). This low threshold makes small environmental changes, that impact large populations, practical and feasible.

Additional research has looked at the inverse of physical activity and the pathway by which it may influence health. Some specific sedentary behaviors such as watching TV and driving have also been linked to increased incidence of Type 2 diabetes and indicators of metabolic risk (Frank et al., 2004; Hoehner et al., 2012; McCormack and Virk, 2014; Proper et al., 2011; Sugiyama et al., 2013; Sugiyama et al., 2016). Often, weight gain and obesity are precursors to a range of chronic diseases, but studies have found increased risk of chronic disease from low physical activity regardless of unhealthy weight (McAuley and Beavers, 2014; NunezCordoba et al., 2013). The combination of overweight and inactivity has become increasingly common. Thus, the behavioral effects of built environment, especially those affecting physical activity and sedentary time, influence personal health and the types of health conditions most prevalent in society (McGrath et al., 2015).

Most behavioral researchers into the relationship between built environment and health have naturally posited that the behavioral path is the most direct and strongest pathway linking built environment to health, with physical activity generally outweighing air pollution (Mueller et al., 2015; Tainio et al., 2016) and/or road safety exposures (Schepers et al., 2015). However, researchers that focus on the health impacts of air pollution may offer a different perspective, with mounting evidence showing the adverse impacts of exposure to air pollution on diabetes (den Braver et al., 2018) and cardiovascular disease (Bell et al., 2014; Brook et al., 2010; Franklin et al., 2015; Pope et al., 2006) and childhood obesity (Jerrett et al., 2014). Strategies to promote health along one pathway may have adverse impacts on the other. A holistic understanding of how they interact is required to develop more effective health promotion strategies and to avoid unintended adverse health consequences. For example, high rates of active transportation can potentially lead to regionally desirable reductions of traffic and air pollution (Rabl \& de Nazelle, 2012); however, active forms of transportation may result in increased risk of injury (Schepers et al., 2015) and increased exposure to pollutants through longer travel time and higher inhalation rates (Bigazzi and Figliozzi, 2014). Recent research in London found that gains in health outcomes from physical activity could be partially, if not substantially, offset by adverse exposure to air pollution (Sinharay et al., 2018).

Although the focus of this conceptual framework is to provide an illustrative description of multiple pathways linking built environment to health, the role of individual and contextual 
factors should not be dismissed. Built environments only serve as a conduit for individuals to maintain either healthy or unhealthy lifestyle. Opportunities and risks each individual faces when being situated in that built environment may vary considerably depending on his or her circumstances (Adkins, Makarewicz, Scanze, Ingram, \& Luhr, 2017; Battista \& Manaugh, 2018; Stafford \& Baldwin, 2018). For example, the built environment features hypothesized to increase walking levels for adults may not be the same for children, elderly, or people with disabilities (Molina-García, Queralt, Adams, Conway, \& Sallis, 2017; Rosenberg, Huang, Simonovich, \& Belza, 2013). Social, cultural, and economic forces outside of built environment can also determine individual's access to health-relevant resources. Even though individuals may have good geographic access to health resources, they may not be able to use them if they face sociocultural and economic barriers (Asanin \& Wilson, 2008).

As the science has developed, practitioners from public health and urban planning are increasingly considering the health impacts of proposed changes to the built environment. Far too often, however, the health impacts considered by both practitioners and researchers consider only one of the two or more pathways, giving a false sense of the overall health impact. The complex variation of multiple social and environmental contexts can easily be pushed aside without guiding conceptual models of how the different pathways from built environment and planning interact and collectively impact a range of public health outcomes. The complexity is furthered by the fact that different populations have unique requirements, preferences, and relationships with their environment (van Wee \& Ettema, 2016). Furthermore, there is inconsistency in methods used to measure built environment features relevant to health. With the exception of one study in Canada (Brook, Setton, Seed, Shooshtari, \& Doiron, 2018), there are very few standardized protocols that maximize comparability across different indices and how much they contribute to different aspects of health, especially with regards to physical, behavioral and environmental health.

Failure to integrate behavioral and exposure-based impacts of transportation and land use actions has the potential to misinform public policy and lead to potential adverse health consequences of well-intended interventions in built environment, which involve major "sunk" costs that are nearly impossible to reverse or erase. Therefore, this study seeks to highlight the need for an integrated framework to consider both behavior and exposure-based pathways to guide future studies. Ideally, this will lead practitioners and policy makers to also consider behavior and exposure-based impacts on health when investments are made, and evaluation is conducted. In the following sections, behavioral and exposure-based pathways connecting 
environmental features with health outcomes are described in detail, followed by a discussion of mechanisms to improve their integration in future research and practice.

\section{THE BEHAVIORAL PATHWAY LINKING THE BUILT ENVIRONMENT TO HEALTH}

Land use and transportation are tightly linked: land use patterns can influence the need for transport infrastructure and service; and transportation investments can change land value and impact how land is developed. Travel behavior, in part, reflects that land use patterns which shape one's activity spaces (Frank, 2004) and the presence and quality of the transportation system available for those activities (Ewing and Cervero, 2010). In addition, infrastructure can induce travel behavior by making some modes more competitive through shorter travel times and other aspects of level of service (Frank et al., 2007). Therefore, pedestrian infrastructure can encourage both utilitarian and recreational pedestrian travel (Saelens and Handy, 2008; Wang et al., 2016) by increasing convenience and comfort for pedestrians. Land use is a leading predictor of utilitarian walking (e.g. density and proximity), and, the presence of sidewalks, street design and traffic safety can also support walking (Ewing et al., 2009). Creating walkable environments can encourage additional walking for all people in those environments (Handy et al., 2006) and this may be especially important in low-income communities (Adkins et al., 2017; Smith et al., 2017). Environments can also discourage walking. Sprawling development patterns are often car oriented because it is not convenient to access key destinations by foot. These land use patterns are characterized by low residential density (i.e. mostly single-detached houses); separated commercial developments with large parking lots (e.g. big box stores); and poor street connectivity (e.g. large blocks or low intersection density) (Mackenbach et al., 2014; Wang et al., 2016). These urban characteristics collectively represent "obesogenic" environments (Nelson \& Woods, 2009).

\subsection{Built environment, physical activity, and health}

In North America, many places are designed primarily for the automobile and personal driving which, in turn, reduces walking or biking and increases sedentary time from vehicle travel. More walkable neighborhoods have higher residential density, more land use mix, better street network connectivity, and retail floor area ratio (Frank and Pivo, 1994a; Frank et al., 2010). Longitudinal research suggests that living in more walkable neighborhoods can increase walking for transportation over time (Hirsch et al., 2014). Increasing the number of social destinations, the number of walking destinations, and street connectivity over time has been shown to increase 
This paper was accepted by Journal of Transport and Health. This is an author accepted version.

walking for transportation among older adults (Haselwandter et al., 2015). Longitudinal evidence leveraging quasi-experimental designs is also mounting. Moving to less or more walkable environments also results in the expected changes in physical activity (Giles-Corti et al., 2013; McCormack et al., 2017).

While much of the early work in this field focused on pedestrians, infrastructure for bicycling and transit can also support physical activity. Bicycle infrastructure and landscape design can help generate bicycling trips (Cole-Hunter et al., 2015) and proximity to trails can support commuting by bicycle (Hirsch et al., 2017). Transit use has also been shown to be a significant source of physical activity, leading to more walking and biking (Besser and Dannenberg, 2005; Knell et al., 2018; Lachapelle et al., 2011; Morency et al., 2011). Large transportation investments combined with urban design can promote active transportation (Adams et al., 2015; Knuiman et al., 2014) and decrease the reliance on driving (Frank et al., 2004). Natural experiments are demonstrating that light rail transit and bus rapid transit in the U.S. has the potential to increase active travel (Brown et al., 2015; Durand et al., 2016; Knell et al., 2018; Saelens et al., 2014), although this may be more important for those who are less physically active (Hong et al., 2016). Additional effort to improve access to rail could increase physical activity (MacDonald et al., 2010).

Physical activity decreases the risk of coronary heart disease, hypertension, Type 2 diabetes, some types of cancer, depression, and all-cause mortality (Jeon et al., 2007; Kelly et al., 2014; Sattelmair et al., 2011; Woodcock et al., 2009). In cross-sectional studies, more walkable neighborhoods have been linked to better health as indicated by body mass index (BMI), systolic and diastolic blood pressure, and novel biomarkers of non-communicable disease, such as established risk factors (e.g. lipids for vascular disease) or diagnostic measures (e.g. hemoglobin A1c for diabetes) (Loo et al., 2017). Conversely, time spent in vehicle travel has been associated with reduced physical activity, increased obesity, Type 2 diabetes and indicators of metabolic risk and increased mortality risk (Frank et al., 2004; Goncalves et al., 2014; Hoehner et al., 2012; Jacobson et al., 2011; Lopez-Zetina et al., 2006; Nunez-Cordoba et al., 2013; Pendola and Gen, 2007; Reiner et al., 2013; Sugiyama et al., 2013; Warren et al., 2010).

New studies are capturing changes in the built environment and evaluating these changes with BMI and clinical indicators. For example, neighborhoods with higher rates of walking, cycling and public transit use and where neighborhood leisure time physical activity, diet, and smoking remained consistent over time showed declining incidence of diabetes, as determined from administrative health records, in more walkable places (Creatore et al., 2016). In a longitudinal study of Canadians, moving to a more walkable neighborhood decreased BMI for 
men but not women, controlling for utilitarian walking (Wasfi et al., 2016), suggesting that there are other aspects of walkable neighborhoods that may be supportive of curtailing obesity. Among participants who moved in the Coronary Artery Risk Development in Young Adults (CARDIA) study, walkability was negatively related to blood pressure and positively related to inflammation as indicated by C-reactive protein (Braun et al., 2016). Tracking people who move provides a novel opportunity to evaluate the impacts of changing one's residential built and social environment. This can inform important investments in improving places, in particular, for vulnerable populations. A recent before and after study of downtown Vancouver demonstrated that opening an urban greenway, that was re-appropriated road space from motor vehicles to active modes, reduced vehicle based greenhouse gas emissions and increased active travel (Ngo et al., 2018).

\subsection{Built environment, diet, and health}

Research has linked obesity to a higher risk of cardiovascular disease (Mozaffarian, 2016), respiratory illness (Littleton, 2012; Peters et al., 2018), Type 2 diabetes (Mozaffarian, 2016), arthritis (Stavropoulos-Kalinoglou et al., 2011), some cancers (Arnold et al., 2016), and poor mental health (Magallares and Pais-Ribeiro, 2013). In addition to physical activity, the built environment can influence diet and thus obesity through access to healthy foods and exposure to unhealthy food environments (Mozaffarian, 2016). Early research in the U.K. identified neighborhood patterns and obesity risk (Ellaway and Macintyre, 1996) and raised awareness for "food deserts". More recent studies confirm a relationship between the food environment and obesity, although findings can vary by how food access is measured and the types of food establishments and other demographic characteristics (Abeykoon et al., 2017; Gamba et al., 2015).

The majority of studies to date are cross-sectional, with heterogeneous methods, study populations, and population characteristics, making it difficult to draw conclusions (GordonLarsen, 2014). As the field matures, longitudinal studies are verifying causality, particularly among sub-populations. For example, the CARDIA study found that fast food availability within 3 kilometers of one's home was tied to consumption among low-income men but not women; however, other aspects of the food environment were either unrelated or mixed (Boone-Heinonen

et al., 2011). Among diabetes patients, proximity to healthy foods was associated with weight loss over time, but only for those who did not move (Laraia et al., 2017). Other natural experiments indicate that the opening of a grocery establishment alone may not impact consumption and BMI (Abeykoon et al., 2017; Woodruff et al., 2018). These differences may represent different needs, 
preferences, and norms between subgroups. In addition, personal and neighborhood transportation and food environments in work places may affect food choices.

Most assessments of diet use distance and density measures to characterize the food environment, although many fail to address underlying land use and transportation characteristics (Gamba et al., 2015). Density may be more relevant for "exposure" to food environments and other measures may be more important for access and active transportation (Gamba et al., 2015).

For example, in a study of low-income populations that examined distance to main food store and transportation mode, distance and mode choice was not predictive of fruit and vegetable intake; yet transit users had lower BMI (Fuller et al., 2013). This study did not evaluate physical activity; however, it is possible that differences in BMI were due to the physical activity that can be attributed to travel mode.

In addition, researchers are starting to add clinical outcomes to neighborhood obesity research. Among New York City adults with diabetes, residential characteristics that included the socioeconomic environment, the food environment, and walkability were associated with better glycemic control and lower hemoglobin A1c (Tabaei et al., 2018). Longitudinal data from the Framingham Heart Offspring and Generation Three Study indicate that neighborhoods with higher intersection density, higher food store density, and less greenspace at baseline were associated with a small increase in adiposity (BMI) at follow-up; higher intersection, fast food, and supermarket density at baseline were associated with smaller increases in fasting glucose (Lee et al., 2017). These analyses did not incorporate physical activity levels at baseline or follow-up. Longitudinal studies that examine how improved walkability and food environments impact multiple health behaviors - diet and physical activity - and clinical outcomes will propel the field forward.

\subsection{Built environment, social interaction, and health}

People need social interaction for physical and mental health. As early as 1979, Berkman and Syme found that longitudinally people with fewer social and community ties were more likely to die earlier, even after controlling for health status and health behaviors (Berkman and Syme, 1979). Today, a number of studies support this early finding. In a meta-analysis of 148 studies, a likelihood of survival for people with stronger social relationships increased by fifty percent (Holt-Lunstad et al., 2010). Social ties can affect behavioral, psychological, and physiologic health by influencing healthy behavior norms, providing social support, and increasing access to opportunities via social networks (Berkman et al., 2000). 
This paper was accepted by Journal of Transport and Health. This is an author accepted version.

The built environment can affect social outcomes by providing public and social spaces and by expanding transportation opportunities for social journeys and access to employment. Several broad features of the built environment may promote or hinder community social interactions: roads and traffic (Anciaes et al., 2016; Mindell and Karlsen, 2012), walkability (Mazumdar et al., 2017), and commuting patterns (Besser et al., 2008; Christian, 2012; Delmelle et al., 2013; Mattisson et al., 2015). Urban sprawl and the spatial distribution of affordable housing and employment can also affect commute time and mode, squeezing out other health and social activities (Besser, Marcus, \& Frumkin, 2008; Christian, 2012). Commute mode may affect social opportunities or enhance social capital through travel behavior that supports more social interactions. For example, among Swedish workers, commuting by vehicle was associated with lower social participation and trust compared to active commuters (Mattisson et al., 2015). An Atlanta based study investigated relationships between built environment features and several aspects of sense of community combined into an index. The study found significantly higher levels of sense of community for participants who lived in places with more walkable locally serving retail but significantly less sense of community for those with more auto oriented, nonlocally serving shops and services (Wood et al., 2010). Finally, better access to transportation can reduce social exclusion and social isolation (Holt-Lunstad et al., 2010) which can be addressed via physical accessibility and through cost. For example, in a study of London's concessionary public transportation program, entitled groups (youths and older adults) reported a sense of value and community inclusion (Jones et al., 2013).

In contrast to the prevailing notion about the positive aspects of social capital, there is a growing recognition that bonding forms of social capital without bridging forms may sometimes work against enhancing health. For example, by excluding outside members from gaining access to resources tied to a network (Carpiano, 2006, 2007). A recent workshop on social aspects of transportation held in Oxford in 2012 highlights the importance of this interdisciplinary thinking and has proven useful in advancing the emerging field of transport, social capital, and health (Schwanen et al., 2015). Yet, few studies exist that attempt to directly link the built environment, social networks, and clinical outcomes related to mental health and depressive symptoms. Given the complexity of the social capital theories and their implications for policy and research, this line of work will particularly benefit from multiple disciplines collaborating, including such fields as public health, sociology, political science, geography, and transportation. 


\section{THE EXPOSURE PATHWAY LINKING BUILT ENVIRONMENT TO HEALTH}

Built environments also affects health through exposure pathways: air pollution, noise, road traffic injuries and crime. These exposure pathways, when combined with the dominant physical activity pathway, form the basis of understanding the etiology of various chronic diseases; and how and why the built environment affects exposure to environmental stressors and subsequent health effects. For example, living in a walkable neighborhood can promote an active and healthier lifestyle. However, if the neighborhood is too close to pollutant sources, e.g. highways or industrial complexes, then living in such neighborhoods can erode some of the health benefits from a more active lifestyle by increasing exposure to countervailing mechanisms (Hankey et al., 2017). The field is currently attempting to understand the independent and joint effects of air pollution and noise on direct health outcomes (Kalsch et al., 2014; Tzivian et al., 2016). The following sections detail the existing and emerging literature that attempt to explain the mechanisms and to provide evidence linking built environment to health through the exposure pathways.

\subsection{Built environment, transportation, and air pollution}

The configuration of the built environment affects how people travel and, therefore, emissions generated from transportation. Previous studies have found that sprawling development leads to reliance on cars for transport, thereby resulting in higher levels of greenhouse gas (GHG) emissions and air pollution (Ewing et al., 2015; Frank and Pivo, 1994b). While the built environment and travel behavior are closely linked to the total amount of emissions being generated, personal exposure to air pollution is complicated by various factors, such as proximity to traffic, intersection density, presence of open space, and physical exertion (Xu et al., 2016; Zhou and Levy, 2007; Zwack et al., 2011). Urban form and morphology, such as street network, building height, and vegetation also affect concentration of pollutants in highly built-up urban areas by changing the microclimate and local wind characteristics (Abhijith et al., 2017; Seaman, 2000; Vardoulakis et al., 2003). For example, compact and walkable neighborhoods may allow people to reduce their daily travel distance, and hence decrease total vehicle emissions (Frank et al., 2000; Stone Jr. et al., 2007; Ye et al., 2017). However, compact and dense development may also increase exposure to localized emissions by placing people closer to emission sources (Hankey et al., 2017; Jerrett et al., 2014; Marshall et al., 2009; Schindler and Caruso, 2014). These interactions, therefore, suggest that some populations are more exposed to health risks from pollutants than others and are also more physiologically sensitive to these exposures. 


\subsection{Transport related air pollution and health}

Of many pollutants generated from anthropogenic activities, some of the most harmful pollutants are linked to traffic emissions: gaseous particles $\left(\mathrm{PM}_{10}, \mathrm{PM}_{2.5}\right.$, and black carbon, and ultrafine particles); volatile organic compounds (VOC), and nitric oxide (NOx); and the mixtures of NOx and VOCs that form ground-level ozone (World Health Organization, 2013). There are several plausible biological mechanisms that link air pollution exposure with chronic health effects (Feng et al., 2016; Ji et al., 2018; Rao et al., 2018; Wang et al., 2017). One plausible mechanism is that repeated inhalation of particulate air pollution through respiratory tract causes oxidative stress leading to systemic inflammation (Nel, 2005). This pollution-related inflammation may lead to increased blood coagulation, accelerated atherosclerosis progression, and ultimately precipitation or aggravation of cardiovascular events (Seaton, MacNee, Donaldson, \& Godden, 1995; van Eeden, Yeung, Quinlam, \& Hogg, 2005). Another plausible mechanism by which air pollution influences health is that smaller inhaled particles can pass directly into blood stream and affect circulatory system, causing adverse effects on physiological control of automatic nervous system that ultimately leads to chronic conditions, such as cardiovascular disease, respiratory disease, and diabetes (Gerritsen et al., 2001; Nel, 2005; NRC, 1998)

The link between air pollution exposure and cardiovascular disease is well established through both clinical and epidemiological studies (Brook et al., 2010). There is also strong evidence that exposure to traffic-related air pollution is related to acute respiratory health problems, such as increased incidence of and exacerbation of asthma, decreased lung function, bronchitis, chronic obstructive pulmonary disease, and other respiratory diseases (Gan et al., 2013; Gasana et al., 2012; Hoek et al., 2013; Brauer, Reynolds, \& Hystad , 2013). These impacts have been observed in several studies (Brauer et al., 2013; Gan, FitzGerald, Carlsten, Sadatsafavi, \& Brauer, 2013; Lin, Ji, \& Liao, 2013) and include exacerbation (Brauer et al., 2013; Lin et al., 2013) and development of asthma (Clark et al., 2009) and chronic obstructive pulmonary disease (COPD) (Gan et al., 2013). Recent evidence also suggests that several common air pollutants (particulate matter, nitrogen dioxide, and ozone) contribute to higher risk for incident Type 2 diabetes (den Braver et al., 2018; Janghorbani et al., 2014; Park et al., 2015). Five prospective cohort studies, with varying geographic contexts, population characteristics, and exposure metrics, have assessed the association of air pollution with diabetes (Andersen et al., 2012; Chen et al., 2013; Krämer et al., 2010; Park et al., 2015). Recent meta-analyses based on these studies reported increased relative risks of type 2 diabetes per $10 \mu \mathrm{g} / \mathrm{m} 3$ increase in exposure to PM2.5 
and to NO2, although there was heterogeneity between genders with larger effects generally reported for women (Eze et al., 2015).

Air pollution exposure has been also linked to psychological symptoms, such as anxiety, changes in mood, cognition and behaviour change (Lundberg, 1996). A large cohort study of women nurses found that exposure to $\mathrm{PM}_{2.5}$ was related to increased levels of anxiety, and the association was stronger for exposures in the month immediately preceding the anxiety measurement. Similarly, a positive association between air pollution exposure and depressive symptoms were found in recent prospective cohort studies of older adults conducted in Korea (Lim et al., 2012) and in the US (Power et al., 2011). Alzheimer's disease and dementia have been also related to long-term exposure to traffic-related air pollution in recent cohort studies from Sweden (Oudin et al., 2016) and Taiwan (Jung, Lin, \& Hwang, 2015).

\subsection{Built environment, noise, and health}

Noise, defined as 'unwanted' sound, is the most complained-about nuisance and affects stress levels and sleep quality of urban residents (Basner and McGuire, 2018). Unhealthy noise is generated and managed in urban areas through land use and zoning regulations (Basner and McGuire, 2018; Moudon, 2009). Previous studies have found that traffic, density, urban form elements and urban morphology, such as open space, building facades, shapes and positions, can significantly influence urban noise levels (Salomons and Berghauser Pont, 2012; Silva et al., 2014).

Noise exposure has been linked to a broad range of chronic health problems, including hypertension and cardiovascular disease (Kalsch et al., 2014; Munzel et al., 2014), diabetes (Dzhambov, 2015), and mental health (Dzhambov et al., 2017; Orban et al., 2016; Sygna et al., 2014). The link between traffic, noise, and health is most developed for cardiovascular health with hypertension, myocardial infarction, and stroke seen in epidemiological literature(Munzel et al., 2014). For example, a growing body of research has found that chronic exposure to noise is associated with an increased risk of diabetes (Eriksson et al., 2014; Ising \& Kruppa, 2004; Sørensen et al., 2013).

There are two biological mechanisms that explain the link between noise and health: hormonal and sleep disruption. For diabetes, in particular, noise-induced stress has been shown to inhibit $\beta$-cell insulin secretion (Liu et al., 2016), increasing the risk of diabetes. Sleep disruption and deprivation may lead to increased fasting glucose, decreased appetite modulation, and overall dysregulation of the endocrine and metabolic functions (Dzhambov, 2015). Noise provokes a variety of stress response, which in turn, affects the cortisol levels (Ising \& Braun, 2000) and may 
result in an adverse effect on glucose tolerance and insulin sensitivity (Spreng, 2000) - a mechanism observed in animal laboratory studies (Liu et al., 2016). A meta-analysis of nine relevant studies has revealed that while residential exposure noise is linked to higher risk of type

2 diabetes, occupational noise exposure was not associated with higher risk (Dzhambov, 2015).

Researchers have noted that increased chronic stress, disturbed sleep, and persistent high cortisol responses are also mental health risk indicators (Ising \& Braun, 2000). For example, a recent prospective cohort study of German adults has found that long-term exposure to traffic noise for five years has been shown to increase the risk of depressive symptoms, and high depressive symptoms at follow-up were more prevalent among female participants (Orban et al., 2016). Although the link between noise and health is well established, there are little research that attempt to comprehensively assess the noise-related health implications of the built environment. However, the research on noise and health is a fast-growing area in public health, and incoming longitudinal evidence with clinical measures will likely advance this field further.

\subsection{Built environment and traffic safety}

Traffic safety is a key challenge of transportation planning which has long addressed injuries and fatalities - including standardized guidance on monetizing the costs for economic analysis using Value of Statistical Life (US DOT, 2016). For example, Vision Zero is the current embodiment of the joint public health and planning efforts to continually reduce traffic fatalities (Vision Zero Network, 2018). Attention remains firmly on reducing risky behaviors such as drunk or distracted driving (Klauer et al., 2014); setting lower speeds (McCarthy, 2001; Stuster, Coffman, \& Warren, 1998); and designing safer roads (Bunn, 2003).

Researchers continue to grapple with the tradeoffs between traffic safety and other health. This is seen most clearly lines in lines of research that investigate the safety benefits and risks of active travel. For example, studies have shown that transit access and walkability increase injury, although this appears to occur because the impact of built environment features on safety is mediated through pedestrian activity (Clifton et al., 2009; Ukkusuri et al., 2012). Urban form that naturally supports walking and biking simultaneously increases safety, particularly when designed for all users (Schepers, Lovegrove, \& Helbich, 2019). Land use patterns such as forming compact regional centers or allowing sprawl; street characteristics such as separation of active modes from vehicular traffic, posted vehicular speed, pedestrian infrastructure, and roadway design; and on the ground conditions including traffic volumes, traffic speed, and pedestrian visibility all influence pedestrian injury rates (Götschi et al., 2015; Stoker et al., 2015; Yu, 2015). If the policy goal is to encourage people to walk and bike for transportation to increase 
health, it is crucial to incorporate traffic safety countermeasures to support these activities as pedestrians and cyclists more vulnerable to injury than other road users (Beck et al., 2007; Blaizot et al., 2013). Longitudinal assessment of the California Safe Routes to School Program, a program that provides funding for traffic safety countermeasures, demonstrated a reduction in collisions for active travelers of all ages (Ragland et al., 2018).

The field continues to document differential effects for varying populations and contexts. For example, the relationship of the built environment and safety may differ by age. Young children require environmental designs that minimize distraction while older adults may need more time and mobility supports (Haselwandter et al., 2015; Rothman et al., 2014; Stoker et al., 2015). Finally, Understanding the injury and fatality rates of active modes continues to suffer from challenges of properly defining exposure (Beck et al., 2007; Götschi et al., 2015) and understanding the 'safety in numbers' effect, meaning that the higher levels of bicycling and walking, the more improved safety (Elvik and Bjørnskau, 2017). New technologies including driverless cars, e-Bikes, and e-Scooters will or are already are having major impacts on pedestrian safety and will be central themes of future research in this area.

\subsection{Built environment, personal safety, and health}

The built environment also influences personal safety and health by discouraging crime and increasing a sense of well-being. The mechanisms by which crime influences physical and mental health are more varied (Blair et al., 2014). Unsafe environments, both perceived and real, influence health by inhibiting walking and use of parks (Kerr et al., 2015; Yu and Lippert, 2016). Neighborhood disorder, crime, and perceived lack of safety increase stress and depression (Henderson et al., 2016; Lorenc et al., 2012). Safety is particularly important to certain subpopulations. Women who feel safe from crime and traffic are more likely to participate in active modes of transportation ( $\mathrm{Yu}$ and Lippert, 2016). Seniors who feel safe from crime and traffic fatalities are more likely to participate in active modes of transportation (Won et al., 2016).

Pedestrian environment or "microscale" features of streetscapes including seating, lighting, street furniture, sidewalk characteristics, surveillance from adjacent buildings and their height and setback, street width, and crossing design appear to influence healthy behavior and mental well-being through signifying a sense of safety. Audit tools such as Microscale Audit of Pedestrian Spaces (MAPS) measures aforementioned streetscapes features and the Environmental Assessment of Public Recreation Spaces (EAPRS) measures graffiti, openness, lighting, trash, condition of parks and greenspace (Cain et al., 2014; Saelens et al., 2006). Studies have found that a protective effect of green space is mediated by supporting physical activity, filtering out air 
This paper was accepted by Journal of Transport and Health. This is an author accepted version.

pollution, increasing social engagement, and reducing depression (Gascon et al., 2015; James et al., 2016). Green space is increasingly linked to reduced crime rates (Bogar and Beyer, 2016) and alleviates mental fatigue by serving as a buffer for stressful life events (van den Berg et al., 2010; van den Bosch and Ode Sang, 2017). A recent study based in Sacramento, California found that a 10 percent increase in tree canopy was associated with an 18 percent reduction in the odds of being obese, suggesting trees can shade uninviting routes and increase physical activity (Ulmer et al., 2016). One important missing puzzle in linking greenspace to health, particularly mental health, is the role of security and safety perception (Hong et al., 2018). Future studies using a stronger longitudinal design will be needed to confirm whether the relationship between greenspace and mental health is robust and to what extent security and safety could mediate or moderate that relationship (Astell-Burt, Mitchell, \& Hartig, 2014).

\section{A RESEARCH AGENDA}

\subsection{Direct, longitudinal evidence linking built environment to health}

Currently, much of the evidence between the built environment and health outcomes focused on a link within a chain of factors show in Figure 1 as part of a causal pathway. This requires predicting downstream impacts based on upstream relationships and piecing together multiple sequential relationships and pivoting from one into the next to form a single prediction. For example, the link between physical activity and health is indisputable, and the evidence that built environments can influence travel behavior and thus physical activity is also solid. However, the studies that include multiple built environment characteristics, physical activity, and health outcomes beyond obesity are limited. This introduces uncertainty in predictive tools that are now being applied in planning practice. Similarly, it is clear that transportation and land use influence air quality and other environmental pollutions that serve as key exposure risk factors for chronic diseases.

Yet, the field still struggles to incorporate the entire pathway into a single study design. Studies that include chronic disease endpoints require large sample sizes to detect statistically significant relationships whereas studies to assess behavioral relationships require instrumentation to capture objective assessment and are seldom feasible on larger samples. Studying and modeling the complete pathway is critical in understanding mediating and moderating factors. Moreover, because the behavioral and exposure pathways may differ by context, particularly for sensitive low-income and racial minorities, attention to study design to 
appropriately and accurately measure differential impacts is needed to target seemingly intractable health disparities for these sub-populations.

While the cross-sectional evidence is compelling, understanding both behavioral and exposure pathways from built environments to health requires longitudinal study designs to establish causality. It is possible that people, especially those with higher incomes, choose to live in environments to support certain behaviors. Most longitudinal evidence linking the exposure and behavioral pathways is primarily of quasi-experimental design. For example, a handful of studies have examined light rail transit and health prior to and after implementation (Brown, Werner, Tribby, Miller, \& Smith, 2015; Hong, Boarnet, \& Houston, 2016; Knell et al., 2018; Saelens, Moudon, Kang, Hurvitz, \& Zhou, 2014). However, very few of these studies explicitly link to health outcomes beyond body mass index- an important risk factor but not the final clinical end point of interest. There is also a need to focus on biological mechanisms as part of the pathway. For example, a built environment intervention that does not reduce diabetes morbidity might support better glucose control. Longitudinal studies - and particularly those that incorporate biomarkers - are resource heavy; however, a wide availability of mobile technology (Kumar, Nilsen, Pavel, \& Srivastava, 2013) coupled with biobank-type studies (Sudlow et al., 2015) will revolutionize the scope of large scale scientific research and will contribute to our understanding of the complex relationships between environmental stressors, genetics, and markers of chronic diseases. Supporting this research will require commitment across a multitude of government agencies to fund long-term studies that increase the understanding of these links. Researchers are beginning to adopt innovative causal methods and Systems Science methods to overcome the challenges of traditional research and to address the complexity of systems, which, can include thresholds, dominate pathways, feedback loops, and adaption. Supporting these efforts will include additional training and broader collaboration than we have seen to date.

\subsection{Investigating behavioral and exposure pathways concurrently}

The central thesis of this paper is the need to capture both behavior and exposure related impacts in a single framework. A significant challenge in the field of built environment and health is understanding the relative impact of the various pathways from planned intervention to health. Because each pathway is associated with a different set of knowledge base and expertise, it is not unusual for everyone on a multi-disciplinary team to be convinced their link is the most important target. The current consensus is that - based on the sheer magnitude of the burden of disease -physical activity has the link of greatest magnitude. However, this is not well proven, 
and it is plausible expect that the ratio of behavioral benefits to exposure risk varies significantly in space, over time, and across population subgroup.

The tendency to analyze interventions - particularly in long range transportation planning - over an entire region exacerbates this challenge since regional exposure trends are likely very different than localized risks. To better support decisions and mitigation measures associated with exposure risks, spatially precise, observation specific research consistent with an ecological model of health is required. Longitudinal studies that concurrently measure behavior and exposure are needed to better understand the importance of mitigating undesirable exposure impacts so that the potential physical activity benefits are realized. These studies need to include all modes of travel and capture the built environment contexts - including mircoscale features that could be mitigating or exacerbating individual exposure.

\subsection{Building tools for policy and practice}

Translating research findings into practice-based tools is a fundamental need for both the planning and public health fields; the past few years has resulted in several large-scale tool development projects to quantify health impacts. Most health and built environment tools are developed to apply relationships culled from the literature. As a collection, the tools available to practitioners do have the ability to address different pathways, but often at the expense of other methodological challenges and/or increased data input requirements.

For example, Health Economic Assessment Tool (HEAT) and the Integrated Transport and Health Impact Model (ITHIM) each use the relative risks to move from exposure to health. HEAT manipulates assumptions about active transportation to calculate exposure to physical activity and then applies relative risks of physical activity to estimate all-cause mortality (Kahlmeier et al., 2017). ITHIM extends this approach to include morbidity; ITHIM also has traffic safety and particulate matter modules (Woodcock, Givoni, \& Morgan, 2013). Both ITHIM and HEAT estimate the impact in a single horizon year, although HEAT does account for the phasing in of the anticipated effects. ITHIM is being extended into via the Towards an Integrated Global Transport and Health Assessment Tool (TIGTHAT) under development in order to investigate the tradeoffs between physical activity, air pollution, and road traffic injuries in a more international setting (Woodcock et al., 2017).

Dynamic Model for Health Impact Assessment (DYNAMO-HIA) DYNAMO-HIA also uses relative risks, but through a Markov chain approach is able to more dynamically reflect the change health behaviors or exposures. A comparison of the DYNAMO-HIA and HEAT tools in a transportation context suggests that the dynamic approach significantly reduces the overall 
This paper was accepted by Journal of Transport and Health. This is an author accepted version.

estimated impact (Mansfield \& Gibson, 2015). Still, each of the previous tool requires "preprocessing" to estimate the active travel and/or physical activity changes that serve as the primary input. Further, while the relative risks in the tools are typically gender and age specific, racial differences are ignored. The California and National Public Health Assessment Models address many of these limitations by address matching a large sample of health prevalence survey participants with detailed built environment data who have reported physical activity and diet, BMI, and health outcomes form a single integrated causal pathway (Urban Design 4 Health, 2017; Schoner et al., 2018). This approach offers the ability to spatially join air pollution, noise, and injury risk to participant home and/or work environments and address both behavioral and exposures based impacts of the built environment. The resulting tools have been applied successfully to assess health impacts of the Los Angeles and San Joaquin Region's long range transportation plans. Further advancements include joining electronic medical records with reported participant data to gain clinical diagnosis and health expenditures and cost.

\subsection{Monetizing the health impacts of built environment}

The health outcomes associated with changes to the built environment can incur significant costs or benefits to society. If impacts are adverse, costs can strain the capacity of the health care system. A recent estimate put the direct health care expenditures attributable to physical inactivity in the U.S. at $\$ 24.7$ billion with another $\$ 3.06$ billion in reduced productivity (Ding et al., 2016). Capturing the monetary benefits of healthy urban design allows for an "apples to apples" comparison of healthy, active living-oriented design with other investments. Therefore, economic appraisal is increasingly considered as an effective tool to lead tangible shifts in policy and planning, and has been incorporated in many existing health impact assessments (Health Canada, 2003; Mindell, Boltong, \& Forde, 2008; Veerman, 2005).

However, adding another discipline - economics - into the multi-disciplinary space of built environment and health presents its own challenges (American Public Health Association, 2010; Brown et al., 2016; Sturm, 2005). Even though multiple frameworks currently exist for monetizing health - value of statistical life, cost of illness, cost-effectiveness, health-related productivity costs to name a few (Akobundu, Ju, Blatt, \& Mullins, 2006; de Blaeij, Florax, Rietveld, \& Verhoef, 2003; Kuchler \& Golan, 2009; Neumann, Sanders, Russell, Siegel, \& Ganiats, 2016)- each method has its own strength and weakness, particularly in the context of the built environment. With multiple metrics available and in use, the advantage to monetizing built environment health changes for the "apples to apples" comparison between pathways quickly 
This paper was accepted by Journal of Transport and Health. This is an author accepted version.

becomes more complicated. Additional theoretical and methodological justification is needed in this area to advance the field for policy applications.

Monetization methods are dependent on the methodology used to model health change and not all methods are equally transferrable to all pathways. For example, the value of statistical life (VSL) can be used to monetize modeling built environment induced mortality changes as used by the World Health Organization's Health Economic Analysis Tool (HEAT) (World Health Organization, 2018). Mortality-VSL applications appear to be the most common application (Brown et al., 2016); however it is important to recognize that VSL represents a societal value of reduced risk of death rather than real expenditures that would be avoided due to increased health. Since targeting chronic disease is somewhat driven by a desire to "bend" the healthcare cost curve, monetizing morbidity by capturing real economic output changes from both decreased health expenditures - known as "direct" costs - and increased productivity from less absenteeism and disability - known as "indirect" costs as gathered from the "cost of illness" (COI) literature might be more appropriate. The COI is a well-developed health econometric modeling that accounts for common comorbidities and builds on large national surveys (Akobundu et al., 2006).

Monetizing health will require additional methodological development for application to the built environment. Outside of WHO's HEAT, applications have limited adoption of standard econometric techniques such as phasing in the intervention and/or discounting to present value (Brown et al., 2016). Monetized direct and indirect benefits could be better integrated into larger economic exercises - for example as inputs for input-output modeling that is routinely used to understand the induced benefits of transportation infrastructure using a multiplier effect. This approach was incorporated into a recent study using the California Public Health Assessment Model (CPHAM) for the Los Angeles Region's Long-Range Transportation plan which includes $\$ 13$ Billion in funding for active transportation (Urban Design 4 Health and AECOM, 2016). CPHAM was used to estimate rates of chronic disease resulting from the adopted transportation plan. Investments in active transportation within the adopted plan were then monetized to assess health care cost reductions using a cost of illness approach. The study further employed the REMI model, most widely used cost benefit model in transportation decision making, to capture workforce productivity and the multiplier impacts of active transportation infrastructure investment for the 25-year life of the plan. Results showed that every dollar spent on active transportation returned $\$ 8.41$ in economic benefit effect (Urban Design 4 Health and AECOM, 2016). 
This paper was accepted by Journal of Transport and Health. This is an author accepted version.

Finally, the mechanisms for how the built environment and physical activity influence healthcare expenditures - likely through reductions in pharmaceutical and emergency medicine - remain unknown (Kang and Xiang, 2017). Pushing forward on this research will allow for successful framing and decision making at the policy table.

\section{CONCLUSIONS}

Calculating the health impacts of policy decisions related to built environments requires understanding of complex relationships that operate through multiple pathways. Studies that investigate multiple pathways support policy makers in predicting both intended and unintended consequences including changes in active travel, air pollution, noise, and traffic accidents. It helps bolster the policy case for compact, pedestrian oriented design by linking travel behavior to health, mitigating unintended consequences, and making explicit the resulting health care costs and benefits. To monetize the health benefits, several different approaches might be applicable depending on the purposes and needs: the "value of statistical life" (VSL) method, the "cost of illness" method, the "years of life lost (or gained)" method and the "quality-adjusted life years" method (Brown et al., 2016). The CPHAM (Urban Design 4 Health and AECOM, 2016) and NPHAM (Schoner et al., 2018) models offer an integrated approach to directly link objectively assessed built environment features with health outcomes, behaviors, and exposures to air pollution, noise, and injury risk. These models connect with commonly used scenario planning software platforms employed by transportation planners to inform decisions about land use and transportation infrastructure investments. Linking results from these tools with cost-benefit models also employed within transportation offers a way to both estimate health impacts and then to monetize the results within the same frameworks commonly used to inform transportation decision making.

A better understanding of the tradeoffs between behaviors and exposures and how they interactively influence health outcomes, health care utilization, and workforce productivity will help develop effective land use and transport interventions, which will lead to tangible shifts in policy to support community health and wellbeing. There are many opportunities to incorporate health into policy including using health indicators, tools such as scenario planning, and broader monitoring of health outcomes. Incorporating health language into policies and plans may also be effective in setting the context for positive social change; this can help lead to performance-based planning where priorities for funding, projects, and programs are reflective of health considerations. For example, performance based funding tied to the 1991 U.S. Clean Air Act Amendments could be more closely tied to health indicators that address the multiple pathways. 
Further, interdisciplinary collaboration between health, environmental, land use, and transportation will support long-term institutional awareness of health benefits and costs. This, in turn, will help narrow the current divide between policy, planning, sciences, and health care delivery and costs.

\section{REFERENCES}

Adkins, A., Makarewicz, C., Scanze, M., Ingram, M., \& Luhr, G. (2017). Contextualizing Walkability: Do Relationships Between Built Environments and Walking Vary by Socioeconomic Context? Journal of the American Planning Association, 83(3), 296-314. https://doi.org/10.1080/01944363.2017.1322527

Akobundu, E., Ju, J., Blatt, L., \& Mullins, C. D. (2006). Cost-of-illness studies : a review of current methods. PharmacoEconomics, 24(9), 869-890.

Andersen, Z. J., Raaschou-Nielsen, O., Ketzel, M., Jensen, S. S., Hvidberg, M., Loft, S., ... Sørensen, M. (2012). Diabetes incidence and long-term exposure to air pollution: a cohort study. Diabetes Care, 35(1), 92-98. https://doi.org/10.2337/dc11-1155

Asanin, J., \& Wilson, K. (2008). "I spent nine years looking for a doctor": Exploring access to health care among immigrants in Mississauga, Ontario, Canada. Social Science \& Medicine, 66(6), 1271-1283. https://doi.org/10.1016/j.socscimed.2007.11.043

Astell-Burt, T., Mitchell, R., \& Hartig, T. (2014). The association between green space and mental health varies across the lifecourse. a longitudinal study. Journal of Epidemiology and Community Health, 68(6), 578-583. https://doi.org/10.1136/jech-2013-203767

Battista, G. A., \& Manaugh, K. (2018). Stores and mores: Toward socializing walkability. Journal of Transport Geography, 67(August 2017), 53-60. https://doi.org/10.1016/j.jtrangeo.2018.01.004

Berkman, L. F., \& Kawachi, I. (2000). Social epidemiology. Oxford University Press.

Besser, L. M., Marcus, M., \& Frumkin, H. (2008). Commute Time and Social Capital in the U.S. American Journal of Preventive Medicine, 34(3), 207-211. https://doi.org/10.1016/j.amepre.2007.12.004

Brauer, M., Reynolds, C., \& Hystad, P. (2013). Traffic-related air pollution and health in Canada. Canadian Medical Association Journal, 185(18), 1557-1558. https://doi.org/10.1503/cmaj.121568

Brook, J. R., Setton, E. M., Seed, E., Shooshtari, M., \& Doiron, D. (2018). The Canadian Urban Environmental Health Research Consortium - a protocol for building a national environmental exposure data platform for integrated analyses of urban form and health. BMC Public Health, 18(1), 114. https://doi.org/10.1186/s12889-017-5001-5

Brown, B. B., Werner, C. M., Tribby, C. P., Miller, H. J., \& Smith, K. R. (2015). Transit Use, Physical Activity, and Body Mass Index Changes: Objective Measures Associated With Complete Street Light-Rail Construction. American Journal of Public Health, 105(7), 1468-1474. https://doi.org/10.2105/AJPH.2015.302561

Bullard, R. D. (1997). Dumping in Dixie: Race, Class and Environmental Quality. Oxford, UK: Westview Press. 
Bunn, F. (2003). Traffic calming for the prevention of road traffic injuries: systematic review and meta-analysis. Injury Prevention, 9(3), 200-204.

https://doi.org/10.1136/ip.9.3.200

Carpiano, R. M. (2006). Toward a neighborhood resource-based theory of social capital for health: Can Bourdieu and sociology help? Social Science \& Medicine, 62(1), 165-175. https://doi.org/10.1016/j.socscimed.2005.05.020

Carpiano, R. M. (2007). Neighborhood social capital and adult health: An empirical test of a Bourdieu-based model. Health \& Place, 13(3), 639-655. https://doi.org/10.1016/j.healthplace.2006.09.001

Chaix, B., Méline, J., Duncan, S., Merrien, C., Karusisi, N., Perchoux, C., ... Kestens, Y. (2013). GPS tracking in neighborhood and health studies: A step forward for environmental exposure assessment, a step backward for causal inference? Health \& Place, 21C, 4651. https://doi.org/10.1016/j.healthplace.2013.01.003

Chen, H., Burnett, R. T., Kwong, J. C., Villeneuve, P. J., Goldberg, M. S., Brook, R. D., ... Copes, R. (2013). Risk of incident diabetes in relation to long-term exposure to fine particulate matter in Ontario, Canada. Environmental Health Perspectives, 121(7), 804-810. https://doi.org/10.1289/ehp.1205958

Christian, T. J. (2012). Automobile commuting duration and the quantity of time spent with spouse, children, and friends. Prev Med, 55(3), 215-218. https://doi.org/10.1016/j.ypmed.2012.06.015

Clark, N. A., Demers, P. A., Karr, C. J., Koehoorn, M., Lencar, C., Tamburic, L., \& Brauer, M. (2009). Effect of Early Life Exposure to Air Pollution on Development of Childhood Asthma. Environmental Health Perspectives, 118(2), 284-290. https://doi.org/10.1289/ehp.0900916

Cooper, J. F., \& Mcmillan, T. E. (2010). Safe Routes to School Local School Project: A health evaluation at 10 low-income schools. Transportation Research. UC Berkeley. Retrieved from http://escholarship.org/uc/item/37m6x95t.pdf

Dannenberg, A. L., Jackson, R. J., Frumkin, H., Schieber, R. A., Pratt, M., Kochtitzky, C., \& Tilson, H. H. (2003). The impact of community design and land-use choices on public health: a scientific research agenda. American Journal of Public Health, 93(9), 1500. Retrieved from http://ajph.aphapublications.org/cgi/content/abstract/93/9/1500

de Blaeij, A., Florax, R. J. G. ., Rietveld, P., \& Verhoef, E. (2003). The value of statistical life in road safety: a meta-analysis. Accident Analysis \& Prevention, 35(6), 973-986. https://doi.org/10.1016/S0001-4575(02)00105-7

de Nazelle, A. J., Rodriguez, D. A., \& Crawford-Brown, D. (2009). The built environment and health: impacts of pedestrian-friendly designs on air pollution exposure. Science of the Total Environment, 407(8), 2525-2535.

Diez Roux, a V. (2001). Investigating neighborhood and area effects on health. American Journal of Public Health, 91(11), 1783-1789. Retrieved from http://www.pubmedcentral.nih.gov/articlerender.fcgi?artid=1446876\&tool=pmcentr ez\&rendertype $=$ abstract

Dzhambov, A. (2015). Long-term noise exposure and the risk for type 2 diabetes: A metaanalysis. Noise and Health, 17(74), 23. https://doi.org/10.4103/1463-1741.149571

Eriksson, C., Hilding, A., Pyko, A., Bluhm, G., Pershagen, G., \& Östenson, C.-G. (2014). Long- 
This paper was accepted by Journal of Transport and Health. This is an author accepted version.

term aircraft noise exposure and body mass index, waist circumference, and type 2 diabetes: a prospective study. Environmental Health Perspectives, 122(7), 687-694. https://doi.org/10.1289/ehp.1307115

Ewing, R., Schmid, T., Killingsworth, R., Zlot, A., \& Raudenbush, S. (2003). Relationship Between Urban Sprawl and Physical Activity, Obesity, and Morbidity. American Journal of Health Promotion, 18(1), 47-57.

Frank, L. D. (2000). Land Use and Transportation Interaction: Implications on Public Health and Quality of Life. Journal of Planning Education and Research, 20(1), 6-22. https://doi.org/10.1177/073945600128992564

Frank, L. D., Greenwald, M. J., Winkelman, S., Chapman, J., \& Kavage, S. (2010). Carbonless footprints: Promoting health and climate stabilization through active transportation. Preventive Medicine, 50, S99-S105. https://doi.org/10.1016/j.ypmed.2009.09.025

Frank, L. D., Sallis, J., Conway, T., Chapman, J., Saelens, B., \& Bachman, W. (2006). Many pathways from land use to health. Journal of the American Planning Association, 72(1), 75-87. https://doi.org/10.1080/01944360608976725

Frohlich, K. L., Corin, E., \& Potvin, L. (2001). A theoretical proposal for the relationship between context and disease, 23(6), 776-797.

Frumkin, H., Frank, L. D., \& Jackson, R. J. (2004). Urban Sprawl and Public Health: Designing, Planning, and Building for Healthy Communities. Washington, D.C.: Island Press.

Gan, W. Q., FitzGerald, J. M., Carlsten, C., Sadatsafavi, M., \& Brauer, M. (2013). Associations of Ambient Air Pollution with Chronic Obstructive Pulmonary Disease Hospitalization and Mortality. American Journal of Respiratory and Critical Care Medicine, 187(7), 721727. https://doi.org/10.1164/rccm.201211-20040C

Geraghty, A. B., Seifert, W., Preston, T., Holm, C. V, Duarte, T. H., \& Farrar, S. M. (2009). Partnership moves community toward complete streets. American Journal of Preventive Medicine, 37(6 Suppl 2), S420-7. https://doi.org/10.1016/j.amepre.2009.09.009

Gerritsen, J., Dekker, J. M., TenVoorde, B. J., Kostense, P. J., Heine, R. J., Bouter, L. M., ... Stehouwer, C. D. (2001). Impaired autonomic function is associated with increased mortality, especially in subjects with diabetes, hypertension, or a history of cardiovascular disease: the Hoorn Study. Diabetes Care, 24(10), 1793-1798. Retrieved from http://www.ncbi.nlm.nih.gov/pubmed/11574444

Gunier, R. B., Hertz, A., Von Behren, J., \& Reynolds, P. (2003). Traffic density in California: socioeconomic and ethnic differences among potentially exposed children. Journal of Exposure Analysis and Environmental Epidemiology, 13(3), 240-246. https://doi.org/10.1038/sj.jea.7500276

Health Canada. (2003). Economic appraisal/evaluation of projects. In Canadian handbook on health impact assessment Vol. 3 (pp. 50-84). Ottawa, Canada.

Hong, A., Boarnet, M. G., \& Houston, D. (2016). New light rail transit and active travel: A longitudinal study. Transportation Research Part A: Policy and Practice, 92, 131-144. https://doi.org/10.1016/j.tra.2016.07.005

Hong, A., Sallis, J. F., King, A. C., Conway, T. L., Saelens, B., Cain, K. L., ... Frank, L. D. (2018). Linking green space to neighborhood social capital in older adults: The role of perceived safety. Social Science and Medicine, 207(April), 38-45. 
This paper was accepted by Journal of Transport and Health. This is an author accepted version.

https://doi.org/10.1016/j.socscimed.2018.04.051

Houston, D., Li, W., \& Wu, J. (2014). Disparities in exposure to automobile and truck traffic and vehicle emissions near the Los Angeles-long beach port complex. American Journal of Public Health, 104(1), 156-164. https://doi.org/10.2105/AJPH.2012.301120

Ising, H., \& Braun, C. (2000). Acute and chronic endocrine effects of noise: Review of the research conducted at the Institute for Water, Soil and Air Hygiene. Noise \& Health, 2(7), 7-24. Retrieved from http://www.ncbi.nlm.nih.gov/pubmed/12689468

Ising, H., \& Kruppa, B. (2004). Health effects caused by noise: evidence in the literature from the past 25 years. Noise \& Health, 6(22), 5-13.

Jackson, R. J. (2003). The impact of the built environment on health: an emerging field. American Journal of Public Health, 93(9), 1382-1384. Retrieved from http://www.pubmedcentral.nih.gov/articlerender.fcgi?artid=1447976\&tool=pmcentr ez\&rendertype=abstract

Jerrett, M., McConnell, R., Wolch, J., Chang, R., Lam, C., Dunton, G., ... Berhane, K. (2014). Traffic-related air pollution and obesity formation in children: a longitudinal, multilevel analysis. Environmental Health, 13(1), 1-9. https://doi.org/10.1186/1476069X-13-49

Johansson, R. (2009). Vision Zero - Implementing a policy for traffic safety. Safety Science, 47(6), 826-831. https://doi.org/10.1016/j.ssci.2008.10.023

Jung, C.-R., Lin, Y.-T., \& Hwang, B.-F. (2015). Ozone, particulate matter, and newly diagnosed Alzheimer's disease: a population-based cohort study in Taiwan. Journal of Alzheimer's Disease : JAD, 44(2), 573-584. https://doi.org/10.3233/JAD-140855

Kahlmeier, S., Götschi, T., Cavill, N., Fernandez, A. C., Brand, C., Rueda, D. R., ... Racioppi, F. (2017). Health economic assessment tool (HEAT) for walking and for cycling: Methods and user guide on physical activity, air pollution, injuries and carbon impact assessments. Geneva, Switzerland.

Klauer, S. G., Guo, F., Simons-Morton, B. G., Ouimet, M. C., Lee, S. E., \& Dingus, T. A. (2014). Distracted Driving and Risk of Road Crashes among Novice and Experienced Drivers. New England Journal of Medicine, 370(1), 54-59. https://doi.org/10.1056/NEJMsa1204142

Knell, G., Durand, C. P., Shuval, K., Kohl Iii, H. W., Salvo, D., Sener, I., \& Gabriel, K. P. (2018). Transit use and physical activity: Findings from the Houston travel-related activity in neighborhoods (TRAIN) study. Prev Med Rep, 9, 55-61. https://doi.org/10.1016/j.pmedr.2017.12.012

Krämer, U., Herder, C., Sugiri, D., Strassburger, K., Schikowski, T., Ranft, U., \& Rathmann, W. (2010). Traffic-Related Air Pollution and Incident Type 2 Diabetes: Results from the SALIA Cohort Study. Environmental Health Perspectives, 118(9), 1273-1279. https://doi.org/10.1289/ehp.0901689

Kuchler, F., \& Golan, E. (2009). Assigning Values to Life: Comparing Methods for Valuing Health Risks. Agricultural Economic Report No. 784. Washington, D.C.

Kumar, S., Nilsen, W., Pavel, M., \& Srivastava, M. (2013). Mobile Health: Revolutionizing Healthcare Through Transdisciplinary Research. Computer, 46(1), 28-35. https://doi.org/10.1109/MC.2012.392 
Ladabaum, U., Mannalithara, A., Myer, P. A., \& Singh, G. (2014). Obesity, abdominal obesity, physical activity, and caloric intake in US adults: 1988 to 2010. American Journal of Medicine, 127(8), 717-727.e12. https://doi.org/10.1016/j.amjmed.2014.02.026

Leeuw, E. de, Duhl, L., \& O’Neill, M. (2010). Healthy Cities. In R. Hutchison (Ed.), Encyclopedia of Urban Studies (pp. 349-351). 2455 Teller Road, Thousand Oaks California 91320 United States: SAGE Publications, Inc. https://doi.org/10.4135/9781412971973.n131

Lim, Y.-H., Kim, H., Kim, J. H., Bae, S., Park, H. Y., \& Hong, Y.-C. (2012). Air pollution and symptoms of depression in elderly adults. Environmental Health Perspectives, 120(7), 1023-1028. https://doi.org/10.1289/ehp.1104100

Lin, R. Y., Ji, R., \& Liao, W. (2013). Age dependent sex disproportion in US asthma hospitalization rates, 2000-2010. Annals of Allergy, Asthma \& Immunology, 111(3), 176-181. https://doi.org/10.1016/j.anai.2013.06.014

Liu, L., Wang, F., Lu, H., Cao, S., Du, Z., Wang, Y., ... Wang, J. (2016). Effects of Noise Exposure on Systemic and Tissue-Level Markers of Glucose Homeostasis and Insulin Resistance in Male Mice. Environmental Health Perspectives, 124(9), 1390-1398. https://doi.org/10.1289/EHP162

Lopez, R. P., \& Hynes, H. P. (2006). Obesity, physical activity, and the urban environment: public health research needs. Environmental Health, 5(1), 25. https://doi.org/10.1186/1476-069X-5-25

Lundberg, A. (1996). Psychiatric aspects of air pollution. Otolaryngology--Head and Neck Surgery: Official Journal of American Academy of Otolaryngology-Head and Neck Surgery, 114(2), 227-231. https://doi.org/10.1016/S0194-59989670172-9

Mansfield, T. J., \& Gibson, J. M. (2015). Health Impacts of Increased Physical Activity from Changes in Transportation Infrastructure: Quantitative Estimates for Three Communities. BioMed Research International, 2015. https://doi.org/10.1155/2015/812325

McCarthy, P. (2001). Effect of speed limits on speed distributions and highway safety: A survey of recent literature. Transport Reviews, 21(1), 31-50. https://doi.org/10.1080/014416400750059275

Mindell, J. S., Boltong, A., \& Forde, I. (2008). A review of health impact assessment frameworks. Public Health, 122(11), 1177-1187. https://doi.org/10.1016/j.puhe.2008.03.014

Molina-García, J., Queralt, A., Adams, M. A., Conway, T. L., \& Sallis, J. F. (2017). Neighborhood built environment and socio-economic status in relation to multiple health outcomes in adolescents. Preventive Medicine, 105(August), 88-94. https://doi.org/10.1016/j.ypmed.2017.08.026

Morello-Frosch, R., Pastor, M., \& Sadd, J. (2001). Environmental Justice and Southern California's “Riskscape." Urban Affairs Review, 36(4), 551.

Morello-Frosch, R., Zuk, M., Jerrett, M., Shamasunder, B., \& Kyle, A. D. (2011). Understanding the cumulative impacts of inequalities in environmental health: Implications for policy. Health Affairs, 30(5), 879-887. https://doi.org/10.1377/hlthaff.2011.0153

Mueller, N., Rojas-Rueda, D., Cole-Hunter, T., de Nazelle, A. J., Dons, E., Gerike, R., ... Nieuwenhuijsen, M. (2015). Health impact assessment of active transportation: A 
This paper was accepted by Journal of Transport and Health. This is an author accepted version.

systematic review. Preventive Medicine, 76, 103-114.

https://doi.org/10.1016/j.ypmed.2015.04.010

Nel, A. (2005). Air Pollution-Related Illness: Effects of Particles. Science, 308(5723), 804806. https://doi.org/10.1126/science.1108752

Nelson, N. M., \& Woods, C. B. (2009). Obesogenic environments: Are neighbourhood environments that limit physical activity obesogenic? Health \& Place, 15(4), 917-924. https://doi.org/10.1016/j.healthplace.2009.02.001

Neumann, P. J., Sanders, G. D., Russell, L. B., Siegel, J. E., \& Ganiats, T. G. (2016). Costeffectiveness in health and medicine (2nd Editio). Oxford, UK: Oxford University Press.

Ngo, V., Frank, L. D., \& Bigazzi, A. (2018). Effects of new urban greenways on transportation energy use and greenhouse gas emissions: A longitudinal study from Vancouver, Canada. Transportation Research Part D.

NRC. (1998). Research Priorities for Airborne Particulate Matter: I. Immediate Priorities and a Long-Range Research Portfolio. Washington, D.C.: National Academies Press. https://doi.org/10.17226/10957

O’Neill, M. S., Jerrett, M., Kawachi, I., Levy, J. I., Cohen, A. J., Gouveia, N., ... Conditions, S. (2003). Health, Wealth, and Air Pollution: Advancing Theory and Methods. Environmental Health Perspectives, 111(16), 1861-1870. https://doi.org/10.1289/ehp.6334

Orban, E., McDonald, K., Sutcliffe, R., Hoffmann, B., Fuks, K. B., Dragano, N., ... Moebus, S. (2016). Residential Road Traffic Noise and High Depressive Symptoms after Five Years of Follow-up: Results from the Heinz Nixdorf Recall Study. Environmental Health Perspectives, 124(5), 578-585. https://doi.org/10.1289/ehp.1409400

Oudin, A., Forsberg, B., Adolfsson, A. N., Lind, N., Modig, L., Nordin, M., ... Nilsson, L.-G. (2016). Traffic-Related Air Pollution and Dementia Incidence in Northern Sweden: A Longitudinal Study. Environmental Health Perspectives, 124(3), 306-312. https://doi.org/10.1289/ehp.1408322

Park, S. K., Adar, S. D., O’Neill, M. S., Auchincloss, A. H., Szpiro, A., Bertoni, A. G., ... Diez-Roux, A. V. (2015). Long-term exposure to air pollution and type 2 diabetes mellitus in a multiethnic cohort. American Journal of Epidemiology, 181(5), 327-336. https://doi.org/10.1093/aje/kwu280

Pastor, M., \& Morello-Frosch, R. (2014). Integrating Public Health And Community Development To Tackle Neighborhood Distress And Promote Well-Being, 11(11), 1890-1896. https://doi.org/10.1377/hlthaff.2014.0640

Pastor, M., Sadd, J., \& Hipp, J. (2001). Which Came First? Toxic Facilities, Minority Move-In, and Environmental Justice. Journal of Urban Affairs, 23(1), 1-21. https://doi.org/10.1111/0735-2166.00072

Power, M. C., Weisskopf, M. G., Alexeeff, S. E., Coull, B. a, Spiro, A., \& Schwartz, J. (2011). Traffic-related air pollution and cognitive function in a cohort of older men. Environmental Health Perspectives, 119(5), 682-687. https://doi.org/10.1289/ehp.1002767

Rabl, A., \& de Nazelle, A. J. (2012). Benefits of shift from car to active transport. Transport Policy, 19(1), 121-131. https://doi.org/10.1016/j.tranpol.2011.09.008 
Rainham, D., McDowell, I., Krewski, D., \& Sawada, M. (2010). Conceptualizing the healthscape: Contributions of time geography, location technologies and spatial ecology to place and health research. Social Science \& Medicine, 70(5), 668-676. https://doi.org/10.1016/j.socscimed.2009.10.035

Richardson, D. B., Volkow, N. D., Kwan, M.-P., Kaplan, R. M., Goodchild, M. F., \& Croyle, R. T. (2013). Spatial Turn in Health Research. Science, 339(6126), 1390-1392. https://doi.org/10.1126/science.1232257

Rosenberg, D. E., Huang, D. L., Simonovich, S. D., \& Belza, B. (2013). Outdoor built environment barriers and facilitators to activity among midlife and older adults with mobility disabilities. Gerontologist, 53(2), 268-279. https://doi.org/10.1093/geront/gns119

Rowangould, G. M. (2013). A census of the US near-roadway population: Public health and environmental justice considerations. Transportation Research Part D: Transport and Environment, 25, 59-67. https://doi.org/10.1016/j.trd.2013.08.003

Rydin, Y., Bleahu, A., Davies, M., Dávila, J. D., Friel, S., De Grandis, G., ... Wilson, J. (2012). Shaping cities for health: complexity and the planning of urban environments in the 21st century. Lancet, 379(9831), 2079-2108. https://doi.org/10.1016/S01406736(12)60435-8

Saelens, B. E., Moudon, A. V., Kang, B., Hurvitz, P. M., \& Zhou, C. (2014). Relation Between Higher Physical Activity and Public Transit Use. American Journal of Public Health, 1-6. https://doi.org/10.2105/AJPH.2013.301696

Saelens, B. E., Sallis, J. F., \& Frank, L. D. (2003). Environmental correlates of walking and cycling: findings from the transportation, urban design, and planning literatures. Annals of Behavioral Medicine: A Publication of the Society of Behavioral Medicine, 25(2), 80-91.

Sallis, J. F., Cervero, R. B., Ascher, W., Henderson, K. a K. A., Kraft, M. K. K., \& Kerr, J. (2006). An ecological approach to creating active living communities. Annual Review of Public Health, 27(1), 297-322. https://doi.org/10.1146/annurev.publhealth.27.021405.102100

Schepers, P., Fishman, E., Beelen, R., Heinen, E., Wijnen, W., \& Parkin, J. (2015). The mortality impact of bicycle paths and lanes related to physical activity, air pollution exposure and road safety. Journal of Transport \& Health, 2(4), 460-473. https://doi.org/10.1016/j.jth.2015.09.004

Schepers, P., Lovegrove, G., \& Helbich, M. (2019). Urban Form and Road Safety: Public and Active Transport Enable High Levels of Road Safety. In M. Nieuwenhuijsen \& H. Khreis (Eds.), Integrating Human Health into Urban and Transport Planning (1st ed., pp. 383408). Cham, Switzerland: Springer International Publishing. https://doi.org/10.1007/978-3-319-74983-9

Schoner, J., Chapman, J., Brookes, A., MacLeod, K. E., Fox, E. H., Iroz-Elardo, N., \& Frank, L. D. (2018). Bringing health into transportation and land use scenario planning: Creating a National Public Health Assessment Model (N-PHAM). Journal of Transport and Health, 10(April), 401-418. https://doi.org/10.1016/j.jth.2018.04.008

Schwanen, T., Lucas, K., Akyelken, N., Cisternas Solsona, D., Carrasco, J. A., \& Neutens, T. (2015). Rethinking the links between social exclusion and transport disadvantage through the lens of social capital. Transportation Research Part A: Policy and Practice, 
This paper was accepted by Journal of Transport and Health. This is an author accepted version.

74, 123-135. https://doi.org/10.1016/j.tra.2015.02.012

Seaton, A., MacNee, W., Donaldson, K., \& Godden, D. (1995). Particulate air pollution and acute health effects. Lancet, 345(8943), 176-178.

Sørensen, M., Andersen, Z. J., Nordsborg, R. B., Becker, T., Tjønneland, A., Overvad, K., \& Ole Raaschou-Nielsen. (2013). Long-Term Exposure to Road Traffic Noise and Incident Diabetes: A Cohort Study. Environmental Health Perspectives, 121(2), 217-222. https://doi.org/10.1289/ehp.1205503

Spreng, M. (2000). Possible health effects of noise induced cortisol increase. Noise \& Health, 2(7), 59-64.

Stafford, L., \& Baldwin, C. (2018). Planning Walkable Neighborhoods: Are We Overlooking Diversity in Abilities and Ages? Journal of Planning Literature, 33(1), 17-30. https://doi.org/10.1177/0885412217704649

Stuster, J., Coffman, Z., \& Warren, D. (1998). Synthesis of safety research related to speed and speed management. No. FHWA-RD-98-154. Washington, D.C.

Sudlow, C., Gallacher, J., Allen, N., Beral, V., Burton, P., Danesh, J., ... Collins, R. (2015). UK Biobank: An Open Access Resource for Identifying the Causes of a Wide Range of Complex Diseases of Middle and Old Age. PLOS Medicine, 12(3), e1001779. https://doi.org/10.1371/journal.pmed.1001779

Tainio, M., de Nazelle, A. J., Götschi, T., Kahlmeier, S., Rojas-Rueda, D., Nieuwenhuijsen, M. J., ... Woodcock, J. (2016). Can air pollution negate the health benefits of cycling and walking? Preventive Medicine, accepted, 8-11. https://doi.org/10.1016/j.ypmed.2016.02.002

US DOT. (2016). Guidance on Treatment of the Economic Value of a Statistical Life in U.S. Department of Transportation Analyses. Washington, DC.

van Eeden, S. F., Yeung, A., Quinlam, K., \& Hogg, J. C. (2005). Systemic response to ambient particulate matter: relevance to chronic obstructive pulmonary disease. Proceedings of the American Thoracic Society, 2(1), 61-67. https://doi.org/10.1513/pats.200406035MS

van Wee, B., \& Ettema, D. (2016). Travel behaviour and health: A conceptual model and research agenda. Journal of Transport \& Health, 3(3), 240-248. https://doi.org/10.1016/j.jth.2016.07.003

Veerman, J. L. (2005). Quantitative health impact assessment: current practice and future directions. Journal of Epidemiology \& Community Health, 59(5), 361-370. https://doi.org/10.1136/jech.2004.026039

Vision Zero Network. (2018). What is Vision Zero?

Woodcock, J., Givoni, M., \& Morgan, A. S. (2013). Health Impact Modelling of Active Travel Visions for England and Wales Using an Integrated Transport and Health Impact Modelling Tool (ITHIM). PLoS ONE, 8(1), e51462. https://doi.org/10.1371/journal.pone.0051462

Woodcock, J., Tainio, M., Herick de Sa, T., de Nazelle, A., Goel, R., Gouveia, N., ... Brage, S. (2017). Towards an Integrated Global Transport and Health Assessment Tool (TIGTHAT). Journal of Transport \& Health, 5, S99-S100.

https://doi.org/10.1016/j.jth.2017.05.258 
This paper was accepted by Journal of Transport and Health. This is an author accepted version. 